\title{
Commentary: GABA Depolarizes Immature Neurons and Inhibits Network Activity in the Neonatal Neocortex In vivo
}

\author{
Yuri Zilberter* \\ Institut de Neurosciences des Systèmes, Inserm UMR_S 1106, Aix-Marseille Université, Marseille, France
}

Keywords: GABA-action, inhibitory GABA, excitatory GABA, neonatal GABA, depolarizarion, hyperpolarization, in vivo, in vitro

\section{A commentary on}

GABA depolarizes immature neurons and inhibits network activity in the neonatal neocortex in vivo

by Kirmse, K., Kummer, M., Kovalchuk, Y., Witte, O. W., Garaschuk, O., and Holthoff, K. (2015). Nat. Commun. 6:7750. doi: 10.1038/ncomms8750

OPEN ACCESS

Edited by:

Ashok Kumar,

University of Florida, USA

Reviewed by:

Sebastian Cerdan,

Instituto de Investigaciones Biomedicas Alberto Sols, Spain

Alain Marty,

Université Paris Descartes, France

*Correspondence: Yuri Zilberter

yuri.zilberter@univ-amu.fr

Specialty section:

This article was submitted to

Neuropharmacology,

a section of the journal

Frontiers in Pharmacology

Received: 04 October 2015 Accepted: 23 November 2015 Published: 10 December 2015

Citation:

Zillberter Y (2015) Commentary: GABA

Depolarizes Immature Neurons and Inhibits Network Activity in the

Neonatal Neocortex In vivo.

Front. Pharmacol. 6:294.

doi: 10.3389/fphar.2015.00294
The study of Kirmse et al. (2015) provides long-awaited evidence that GABA acts as an inhibitory neurotransmitter in the neonatal brain-the same way it acts in the adult brain. To recap, the concept of GABA acting as an excitatory neurotransmitter in the neonates dominated research for a long time. Based almost exclusively on the in vitro studies (Zilberter et al., 2010; Bregestovski and Bernard, 2012), extrapolations have leads to the theory of excitatory-toinhibitory switch of GABA action and its central role in brain maturation (Ben-Ari et al., 2007, 2012).

In anesthetized P3-4 mice, Kirmse and colleges first showed that GABA application induced a dramatic, 16-fold drop in cortical plate (CP) cell membrane resistance. Then, using non-invasive patch recordings (cell-attached), the authors found that applied GABA did not generate action potentials (APs) in any of the cells. To avoid confounding factors such as anesthetics and brain damage, the authors employed $\mathrm{Ca}^{2+}$ imaging on $\mathrm{N}_{2} \mathrm{O}$-sedated animals keeping the dura-mater intact. In line with electrophysiological data, afferent electrical stimulation readily evoked APgenerated $\mathrm{Ca}^{2+}$ transients in the majority of cells while the cells were nonresponsive in the presence of glutamate receptor blockers, indicating that GABAergic transmission failed to induce APs. In line with these results, the epidural GABA applications failed to induce detectable $\mathrm{Ca}^{2+}$ transients in the vast majority of $\mathrm{CP}$ cells in $\mathrm{P} 1$ and $\mathrm{P} 3-4$ mice.

To clarify the mode of GABA action on network activity, the authors simultaneously recorded correlated field and fluorescence (recorded in some cases through the intact skull in the absence of sedation) responses to spontaneous activity in the intact brain. Recordings revealed spindle-like oscillations resembling spindle burst activity previously described in the visual cortex of neonatal rats (Hanganu et al., 2006; Colonnese et al., 2010). Interestingly, the oscillations were not affected by bumetanide (NKCC1 transporter antagonist which modifies the driving force for $\mathrm{Cl}^{-}$currents via GABAA receptor channels) confirming the absence of GABAergic contribution to the spontaneous network excitation. However, diazepam (benzodiazepine strongly increasing the GABAA receptor channel open time) and gabazine (antagonist of GABAA receptors) strongly modified spontaneous activity inducing its inhibition and amplification, respectively. These results are in contrast to those in slices showing inhibition of spontaneous activity by GABAA antagonists [e.g., blockade of so 
called giant depolarizing potentials, GDPs, by bicuculine and picrotoxine in the original study (Ben-Ari et al., 1989)]. Altogether, the paper results show convincingly that GABAergic transmission provides efficient inhibition of network activity in neonatal mice-definitively the major message of the Kirmse and colleges study.

Regarding the mechanism of inhibition, the authors demonstrated powerful shunting induced by GABA in glutamatergic cells. Another potential factor in observed GABA action is a shift in membrane potential. Indeed, in the process of membrane depolarization during neuronal excitation, GABAergic transmission becomes progressively hyperpolarizing due to increasing driving force for $\mathrm{Cl}^{-}$inward currents. In neonatal slices, however, the values for reversal potential of GABA-induced currents have been found to be so positive in respect to the resting potential (Ben-Ari et al., 2007), that GABA application in neurons could both induce generation of APs and efficiently promote spontaneous network activity (GDPs). The concept of excitation/inhibition switch in the GABA action during early development was created exactly on this background. Kirmse and colleges showed that in vivo, the GABA-induced shift in the membrane potential is either hyperpolarizing or depolarizing (in the majority of cells). The depolarization, however, was of a very small value since neither GABA application nor afferent stimulation evoked detectable $\mathrm{Ca}^{2+}$ transients in the vast majority of cells. Therefore, in vivo GABA-induced depolarization is radically different from that found in slices and does not contribute to the cell excitation.

Meanwhile, based on the authors' data, it is not possible to conclude that GABA action in P3-4 differs qualitatively from that in $\mathrm{P} 1$ or $\mathrm{P} 25-27$. Indeed, the larger number of GABAinduced $\mathrm{Ca}^{2+}$ transients at P1 vs. P3-4 (11/117 vs. 6/204) can be easily explained just by a higher membrane resistance of P1 cells, in contrast to the author's suggestion of higher intracellular $\mathrm{Cl}^{-}$concentration at $\mathrm{P} 1$. As compared with mature cells, hyperpolarization was found in only one cell from 10 in P25-27 vs. 2/15 in P3-4, making any age difference unconvincing. In addition, comparison of the potential shift values does not have any particular meaning since this method (cell-attached patch) does not provide quantitative measurements (Mason et al., 2005). The evident common feature of all mouse groups was that the potential shifted by GABA was very close to the membrane potential at rest. Therefore, the data provided

\section{REFERENCES}

Ben-Ari, Y., Cherubini, E., Corradetti, R., and Gaiarsa, J. L. (1989). Giant synaptic potentials in immature rat CA3 hippocampal neurones. J. Physiol. 416, 303-325. doi: 10.1113/jphysiol.1989.sp017762

Ben-Ari, Y., Gaiarsa, J. L., Tyzio, R., and Khazipov, R. (2007). GABA: a pioneer transmitter that excites immature neurons and generates primitive oscillations. Physiol. Rev. 87, 1215-1284. doi: 10.1152/physrev.00017.2006

Ben-Ari, Y., Khalilov, I., Kahle, K. T., and Cherubini, E. (2012). The GABA excitatory/inhibitory shift in brain maturation and neurological disorders. Neuroscientist 18, 467-486. doi: 10.1177/1073858412438697

Bregestovski, P., and Bernard, C. (2012). Excitatory GABA: how a correct observation may turn out to be an experimental artifact. Front. Pharmacol. 3:65. doi: 10.3389/fphar.2012.00065 by the authors so far support neither the hypothesis of the depolarization/hyperpolarization nor the high $\left[\mathrm{Cl}^{-}\right]_{i} /$ low $\left[\mathrm{Cl}^{-}\right]_{i}$ developmental switch.

Taking into account a small value of GABA-induced potential shift at rest and the absence of significant difference in GABA action between age groups, it is surprising that the authors focused on the issue of "depolarizing GABA." A shift of few $\mathrm{mV}$ above or below membrane potential at rest provided by GABA has an unclear physiological implication and, as the authors agreed, is unlikely to make any significant contribution to the cell excitability.

Therefore, association of this shift with the very concept of depolarizing GABA is misleading since the accurate term for neonatal GABA action has always been "excitatory GABA" (BenAri et al., 2007). The excitatory GABA concept has been seriously questioned in several studies (Rheims et al., 2009; Holmgren et al., 2010; Dzhala et al., 2012), which attempted to find out the reason for such "unusual" GABA behavior in slices. These studies suggested that the increased neuronal $\left[\mathrm{Cl}^{-}\right]_{\mathrm{i}}$ in slices may be the consequence of acute injury of neuronal processes or/and inappropriate metabolic conditions. They showed that correction of these abnormalities [e.g., intact hippocampal preparation used by Dzhala and colleges or enhanced energy metabolism in Rheims et al. (2009) and Holmgren et al. (2010)] resulted in GABA-induced inhibition of spontaneous network activity. Importantly, in respect to the resting potential, GABA was slightly depolarizing in the majority of neurons (e.g., Holmgren et al., 2010) and therefore the categorization of these studies as opposing "depolarizing" (Kirmse et al., 2015) instead of "inhibitory" GABA is factually incorrect.

To conclude, the study by Kirmse and colleges convincingly demonstrated GABA to be an inhibitory neurotransmitter in both developing and mature animals, which should have a big impact in the field of developmental neuroscience. Many important questions are still left for future studies, e.g., what is the developmental profile of $\left[\mathrm{Cl}^{-}\right]_{i}$ and how it relates to the resting membrane potential. However, citing the co-authors' previous publication on the subject, “... an absence of GABAmediated excitation (Rheims et al., 2009; Holmgren et al., 2010) could have major implications for a central hypothesis of developmental neurobiology" (Kirmse et al., 2010). Now, the authors give us the opportunity to reconsider this central hypothesis.

Colonnese, M. T., Kaminska, A., Minlebaev, M., Milh, M., Bloem, B., Lescure, S., et al. (2010). A conserved switch in sensory processing prepares developing neocortex for vision. Neuron 67, 480-498. doi: 10.1016/j.neuron.2010. 07.015

Dzhala, V., Valeeva, G., Glykys, J., Khazipov, R., and Staley, K. (2012). Traumatic alterations in GABA signaling disrupt hippocampal network activity in the developing brain. J. Neurosci. 32, 4017-4031. doi: 10.1523/JNEUROSCI.513911.2012

Hanganu, I. L., Ben-Ari, Y., and Khazipov, R. (2006). Retinal waves trigger spindle bursts in the neonatal rat visual cortex. J. Neurosci. 26, 6728-6736. doi: 10.1523/JNEUROSCI.0752-06.2006

Holmgren, C. D., Mukhtarov, M., Malkov, A. E., Popova, I. Y., Bregestovski, P., and Zilberter, Y. (2010). Energy substrate availability as a determinant of neuronal resting potential, GABA signaling and spontaneous network activity 
in the neonatal cortex in vitro. J. Neurochem. 112, 900-912. doi: 10.1111/j.14714159.2009.06506.x

Kirmse, K., Kummer, M., Kovalchuk, Y., Witte, O. W., Garaschuk, O., and Holthoff, K. (2015). GABA depolarizes immature neurons and inhibits network activity in the neonatal neocortex in vivo. Nat. Commun. 6, 7750. doi: $10.1038 /$ ncomms 8750

Kirmse, K., Witte, O. W., and Holthoff, K. (2010). GABA depolarizes immature neocortical neurons in the presence of the ketone body ss-hydroxybutyrate. J. Neurosci. 30, 16002-16007. doi: 10.1523/JNEUROSCI.253410.2010

Mason, M. J., Simpson, A. K., Mahaut-Smith, M. P., and Robinson, H. P. (2005). The interpretation of current-clamp recordings in the cell-attached patch-clamp configuration. Biophys. J. 88, 739-750. doi: 10.1529/biophysj.104.0 49866

Rheims, S., Holmgren, C. D., Chazal, G., Mulder, J., Harkany, T., Zilberter, T., et al. (2009). GABA action in immature neocortical neurons directly depends on the availability of ketone bodies. J. Neurochem. 110, 1330-1338. doi: 10.1111/j.1471-4159.2009.06230.x

Zilberter, Y., Zilberter, T., and Bregestovski, P. (2010). Neuronal activity in vitro and the in vivo reality: the role of energy homeostasis. Trends Pharmacol. Sci. 31, 394-401. doi: 10.1016/j.tips.2010.06.005

Conflict of Interest Statement: The author declares that the research was conducted in the absence of any commercial or financial relationships that could be construed as a potential conflict of interest.

Copyright $(2) 2015$ Zilberter. This is an open-access article distributed under the terms of the Creative Commons Attribution License (CC BY). The use, distribution or reproduction in other forums is permitted, provided the original author(s) or licensor are credited and that the original publication in this journal is cited, in accordance with accepted academic practice. No use, distribution or reproduction is permitted which does not comply with these terms. 